ORIGINAL ARTICLE

\title{
Association of specific genotype and haplotype of p53 gene with cervical cancer in India
}

\author{
S Mitra, C Misra, R K Singh, C K Panda, S Roychoudhury
}

J Clin Pathol 2005;58:26-31. doi: 10.1136/jicp.2004.019315

See end of article for authors' affiliations .......................

Correspondence to: Dr S Roychoudhury, Human Genetics and Genomics Division, Indian Institute of Chemical Biology, 4, Raja S. C. Mullick Road, Kolkata 700 032, India; susanta_rc@ yahoo.co.in

Accepted for publication 4 August 2004
Background: The predictive value of codon 72 arginine homozygosity at the p53 gene for human papilloma virus associated cervical cancer risk remains inconclusive. It has also been proposed that the inheritance of specific germline haplotypes based on three biallelic polymorphisms of p53 (intron $316 \mathrm{bp}$ duplication, codon $72 \mathrm{Bst} \mathrm{UI}$ (Arg/Pro), and intron $6 \mathrm{Nci}$ I restriction fragment length polymorphism at nucleotide 13494) is a better predictor of various cancer risks.

Aims: To determine the genotype and haplotype frequency of these three p53 polymorphisms in 61 patients with cervical squamous cell carcinoma and 94 ethnically matched controls from the eastern region of India and estimate the risk, if any, of specific genotypes and haplotypes.

Methods: Samples were genotyped by polymerase chain reaction followed by variant specific restriction enzyme digestion. Haplotypes were estimated by the maximum likelihood method using the expectation maximisation algorithm.

Results: Genotype distributions of the three polymorphisms in patients and controls showed a good fit to the Hardy-Weinberg equilibrium. The p53 codon 72 arginine homozygous genotype was significantly over represented in patients compared with controls. Those with the homozygous arginine genotype exhibited a 2.59 fold higher risk of developing squamous cell carcinoma of the uterine cervix. A significant risk was also seen with a combination of two haplotypes, 1-2-1 and 1-2-2.

Conclusion: p53 codon 72 arginine homozygotes appear to be at greater risk of developing squamous cell carcinoma of the uterine cervix. The high risk haplotypes 1-2-1 and 1-2-2 also contain the arginine allele, further strengthening this conclusion.
C ervical carcinoma in women is the second most common type of cancer worldwide. The incidence is greater in developing countries, such as India, where this is the most common female malignancy, with almost 100000 new cases each year. ${ }^{1}$ This disease is one of the major causes of death from cancer in women, with an overall survival rate of $40 \% .^{2}$ Human papillomavirus (HPV) is considered a necessary cause of all cervical cancers. ${ }^{3}$ HPV positivity in cervical cancer is estimated to be between $90 \%$ and $95 \% .{ }^{4}$ Fifteen HPV types have been classified as high risk types $(16,18,31,33,35,39,45,51,52,56,58,59,68,73$, and $82)$; three have been classified as probable high risk types $(26,53$, and 66$)$; and 12 have been classified as low risk types $\left(6,11,40,42,43,44,54,61,70,72,81\right.$, and CP6108). ${ }^{4}$ Among the high risk HPV genotypes, HPV-16 is the most common in squamous cell carcinoma of the cervix (50-60\%), followed by HPV-18, which is present in about $11-15 \%$ of cervical cancer cases. ${ }^{45}$ The viral oncoproteins E6 and E7 of HPV mainly contribute to tumorigenesis. ${ }^{5}{ }^{6}$ The E6 protein interacts with p53 and inhibits its activity, followed by proteolytic degradation through the ubiquitin pathway. ${ }^{78}$ In addition to inducing the rapid degradation of p53, E6 also binds to and degrades FADD, thus preventing the transmission of apoptotic signals via the Fas pathway. ${ }^{6}$ Recently it was shown that sustained inactivation of the p53 pathway by the E6 protein is required for maintenance of the proliferative phenotype of HeLa cervical carcinoma cells. ${ }^{9}$ Because mutation of the p53 gene is a relatively rare event, ${ }^{10}$ abrogation of $\mathrm{p} 53$ function by the E6 protein of HPV is thought to be one of the major events in cervical carcinogenesis.

The possible contribution of inherited polymorphisms in the p53 gene to the development of cancer risk has been the subject of interest after a report that women with the p53 codon 72 arginine homozygous genotype were at higher risk than those with the proline homozygous genotype of developing cervical cancer. ${ }^{11}$ Since then, there have been several reports worldwide, but no definite conclusion has been reached. Some reports revealed a strong association, whereas others did not. ${ }^{12}{ }^{13}$ Two other p53 polymorphisms-a 16 bp duplication at intron 3 and intron 6 Nci I restriction fragment length polymorphism (RFLP) at nucleotide (nt) 13494-have also been studied for their association with different cancer types. Genotypes homozygous for the absence of the Nci I restriction site in intron 6 and the presence of the $16 \mathrm{bp}$ duplication at intron 3 were reported to have an increased risk of lung cancer ${ }^{14}$ and ovarian cancer. ${ }^{15}$ The $16 \mathrm{bp}$ duplication at intron 3 was also found to increase the risk of breast cancer by the age of 50 years for both homozygous and carrier genotypes, ${ }^{16}$ although another study reported no increase in lung cancer risk associated with this particular genotype. ${ }^{17}$

"There are no reports on the analysis of cervical cancer risk using multiple p53 gene polymorphisms and haplotypes constructed from them"

It has also been proposed that the inheritance of specific germline haplotypes based on these three biallelic polymorphisms of p53 (16 bp duplication in intron 3, codon 72 Arg/Pro, and intron 6 Nci I RFLP at nt 13494) is a better predictor of breast cancer, ${ }^{18-21}$ colorectal cancer, ${ }^{22}$ and lung cancer. ${ }^{14}$ The specific haplotype "p53 l-2-1" exhibited a positive association with breast cancer risk. ${ }^{18-20}$

Abbreviations: $\mathrm{Cl}$, confidence interval; $\mathrm{df}$, degrees of freedom; HPV, human papillomavirus; nt, nucleotides; $\mathrm{OR}$, odds ratio; $\mathrm{PCR}$, polymerase chain reaction; RFLP, restriction fragment length polymorphism 
To date, to the best of our knowledge, there are no reports on the analysis of cervical cancer risk using multiple p53 gene polymorphisms and haplotypes constructed from them. Therefore, we sought to examine the allele and genotype frequencies for all three p53 polymorphisms (intron $316 \mathrm{bp}$ duplication, codon 72 Bst UI (Arg/Pro), and intron 6 Nci I RFLP at nt 13494) in 61 patients with cervical cancer and 94 ethnically matched healthy female controls from eastern India. In our study, haplotypes constructed from these three polymorphisms exhibited distinct differences between the case and control subjects. The association of specific p53 genotypes and/or haplotypes with cervical cancers was examined.

\section{MATERIALS AND METHODS}

\section{Sample collection and clinical data}

Sixty one freshly operated uterine cervical tissues and peripheral blood leucocytes from the patients were obtained from the hospital section of Chittaranjan National Cancer Institute, Kolkata, India. Three of the samples were dysplastic and the rest were squamous cell carcinoma type, of which 39 were stages I/II and 19 were stages III/IV. Peripheral blood leucocytes were also obtained from 94 ethnically matched, unrelated, normal, healthy female subjects with no history of cervical lesions recruited through a population screening programme for use as controls. Both patients and controls were from the Bengali speaking caste population of the same city, with a similar low income background. The mean (SD) age of the patients was 46.89 (10.29) years and that of the controls was 47.44 (12.53) years. The tissue samples were frozen immediately after collection and stored at $-80^{\circ} \mathrm{C}$ until use. Written consent was obtained from the patients and controls before sample collection. The internal review committee on research using human subjects cleared the project after careful examination of the protocols. High molecular weight genomic DNA was extracted from the peripheral blood leucocytes and from tissues after microdissection according to the standard procedure. ${ }^{23}$

\section{HPV detection and typing}

The presence of HPV in the cervical lesions was detected by performing the polymerase chain reaction (PCR) using primers (MY09 and MY11) from the consensus L1 region. ${ }^{24}$ Typing of HPV-16/18 in the Ll positive samples was done by means of PCR using specific primers from the E6 region of HPV $-16^{25}$ and the E7 region of HPV- $18 .^{26}$ The PCR products were electrophoresed on a $2 \%$ agarose gel, stained with ethidium bromide, visualised under ultraviolet light, and photographed. For final confirmation of the HPV types, after gel electrophoresis the PCR products were transferred on to a nylon membrane for Southern hybridisation with $\left[{ }^{32} \mathrm{P}\right]$ labelled HPV type specific probes. ${ }^{27}$ DNA from the SiHa (for
HPV-16) and HeLa (for HPV-18) cell lines and the HPV type specific plasmids were used as positive controls.

\section{p53 gene polymorphism analysis}

Three biallelic p53 gene polymorphisms (intron 316 bp duplication, codon 72 Bst UI (Arg/Pro), and intron 6 Nci I at nt 13494) for both patients with cervical cancer and controls were analysed by PCR, followed by variant specific restriction enzyme digestion. ${ }^{28}$ PCR was performed with primers that flanked the two polymorphic sites of the intron $316 \mathrm{bp}$ duplication and the exon 4 Bst UI RFLP, as described elsewhere. ${ }^{28}$ The resulting PCR products were either 432 or 448 bp DNA fragments depending on the absence or presence of the intron $316 \mathrm{bp}$ duplication in the template genomic DNA. Length polymorphism was directly evident from 6\% polyacrylamide gel analysis of the PCR product. An aliquot of the same PCR product was subjected to restriction digestion with Bst UI (New England Biolabs Inc, Beverly, Massachusetts, USA), which generated DNA fragments of four different sizes: $448 \mathrm{bp}$, Bst UI digestion resistant (Pro at codon 72) with the intron 3 duplication; $432 \mathrm{bp}$, Bst UI digestion resistant (Pro at codon 72) without the intron 3 duplication; 246 bp, Bst UI digested (Arg at codon 72) with the intron 3 duplication; $230 \mathrm{bp}$ Bst UI digested (Arg at codon 72) without the intron 3 duplication.

The third polymorphic site (Nci I in intron 6) was PCR amplified separately with flanking primers, as described elsewhere. ${ }^{28}$ Aliquots $(5 \mu \mathrm{l})$ of the reaction mixture containing the $913 \mathrm{bp} \mathrm{PCR}$ fragment were subjected to restriction digestion with Nci I. The digest contained either a $563 \mathrm{bp}$ DNA fragment (in the absence of the polymorphic Nci I site) or a combination of $286 \mathrm{bp}$ and $277 \mathrm{bp}$ DNA fragments (in the presence of the polymorphic Nci I site), together with an invariant 350 bp DNA fragment as a result of the presence of a non-polymorphic Nci I site in the amplified region of the DNA.

Some of the PCR products $(5 \%)$ were sequenced (ABI prism 377; Applied Biosystems, Foster City, California, USA) to confirm the genotypes at all loci, which were determined by PCR and PCR-RFLP methods.

\section{Statistical analysis}

Genotypic distributions were examined for a significant departure from the Hardy-Weinberg equilibrium by a goodness of fit $\chi^{2}$ test. A comparison of the haplotype and genotype distributions was performed by $\chi^{2}$ statistics with Yate's correction whenever required. The frequencies of extended haplotypes were estimated by the maximum likelihood method, using the expectation maximisation algorithm as implemented in the ARLEQUIN software program. Odds ratios (ORs) with $95 \%$ confidence intervals (CI) were computed at http://www.hutchon.freeserve.co.uk.

Table 1 Distribution of p53 genotypes in patients with cervical cancer and normal controls

\begin{tabular}{|c|c|c|c|c|c|c|}
\hline \multirow[b]{2}{*}{ Locus } & \multirow[b]{2}{*}{ Population (N) } & \multicolumn{4}{|c|}{ p53 genotype } & \multirow[b]{2}{*}{$\chi^{2} \mathrm{HW}$} \\
\hline & & $1-1(\%)$ & $2-1(\%)$ & $2-2(\%)$ & p Value & \\
\hline \multirow{2}{*}{16 bp (intron3) } & Cases (61) & $45(73.8)$ & $15(24.6)$ & $1(1.6)$ & \multirow[t]{2}{*}{0.528} & 0.04 \\
\hline & Control (93) & $61(65.6)$ & 29 (31.2) & $3(3.2)$ & & 0.04 \\
\hline \multirow{2}{*}{ Bst UI (Arg/Pro) } & Cases (61) & 12 (19.7) & 30 (49.2) & $19(31.1)$ & \multirow[t]{2}{*}{0.038} & 0 \\
\hline & Control (94) & $29(30.8)$ & 51 (54.2) & 14 (15.0) & & 1.21 \\
\hline \multirow{2}{*}{ Nci I (intron6) } & Cases (52) & $1(1.9)$ & $16(30.8)$ & 35 (67.3) & \multirow[t]{2}{*}{0.687} & 0.29 \\
\hline & Control (84) & $3(3.6)$ & 30 (35.7) & 51 (60.7) & & 0.31 \\
\hline
\end{tabular}

$\mathrm{N}$ is the number of individuals analysed.

1 at an individual locus indicates the absence of a 16 bp duplication at intron 3, a proline at Bst UI, and the absence of Nci I at intron 6.

2 at individual locus indicates the presence of a 16 bp duplication at intron 3, an arginine at Bst UI, and the presence of Nci I at intron 6.

$\chi^{2}$ HW stands for $\chi^{2}$ for deviation from Hardy-Weinberg equilibrium. 
Table $2 \mathrm{HPV}$ and p53 codon 72 genotype distribution in normal controls and patients with cervical carcinoma at different histological stages

\begin{tabular}{|c|c|c|c|c|c|c|}
\hline Cytology/Histology & $\mathbf{N}$ & HPV-16+ & HPV-18+ & p53 Arg / Arg & p53 Arg/Pro & p53 Pro/Pro \\
\hline Normal & 94 & $11(11.7 \%)$ & $6(6.4 \%)$ & $14(15.0 \%)$ & $51(54.2 \%)$ & $29(30.8 \%)$ \\
\hline Dysplasia & 3 & $1(33.3 \%)$ & $1(33.3 \%)$ & $0(0 \%)$ & $3(100 \%)$ & $0(0 \%)$ \\
\hline Cancer stage I+II & 39 & $22(56.4 \%)$ & $9(23.1 \%)$ & $11(28.2 \%)$ & $20(51.3 \%)$ & $8(20.5 \%)$ \\
\hline Cancer stage III+IV & 19 & $14(73.7 \%)$ & $5(26.3 \%)$ & $8(42.1 \%)$ & $7(36.8 \%)$ & $4(21.1 \%)$ \\
\hline
\end{tabular}

$\mathrm{N}$, number of individuals analysed.

HPV, human papillomavirus.

\section{RESULTS}

Table 1 depicts the genotype frequency distribution of three different biallelic DNA polymorphisms in the $\mathrm{p} 53$ gene for the patients with cervical cancer and the ethnically matched normal female control subjects. The codon 72 Bst UI Al allele (proline allele) and the intron $6 \mathrm{Nci}$ I Al alleles are defined by absence of the restriction sites, and the intron $316 \mathrm{bp}$ duplication $\mathrm{Al}$ allele is defined by absence of the duplication. ${ }^{17} 29$ Both the study groups were found to be in HardyWeinberg equilibrium at all three p53 loci (table 1). We found a significant difference in the overall genotype frequency distribution only at the codon 72 locus between the case and control subjects ( $p=0.038$; table 1 ). Individuals with the arginine homozygous genotype exhibited a 2.59 fold higher risk of developing squamous cell carcinoma of the cervix compared with those with the other two genotypes (OR, 2.59; $95 \% \mathrm{CI}, 1.18$ to 5.67$)$. The difference in the numbers of samples genotyped, particularly for the Nci I locus, results from the fact that PCR amplification failed in many of the control subjects, even after repeated attempts.

Table 2 shows the p53 codon 72 genotype distribution in normal controls and patients with HPV positive cervical carcinoma at different histological stages. Overall, we found that 52 of the 61 tumours were HPV positive; 37 and 15 were HPV-16 and HPV-18 positive, respectively. In contrast to a previous report, ${ }^{30}$ we found no coinfection with HPV-16 and HPV-18 in our samples. One possible explanation for this discrepancy is that we isolated the tumour DNA after microdissection of the tumour tissues, thus enriching the DNA specifically from tumour tissue and minimising the possibility of contamination with DNA from adjacent tissues. It has been reported that tumours are clonal with respect to HPV types, but surrounding tissues may be infected by different subtypes, thus leading to cases of coinfection. ${ }^{31}$ It is apparent from table 2 that the frequency of HPV-16 positive tumours increases with advancing histological stages of the tumours. We can make no conclusions regarding early HPV infection because of the small number of dysplastic samples. However, a similar increase in HPV infection with progression of histological stages of dysplasia has been reported. ${ }^{30}$ The frequency of the arginine homozygous genotype was significantly higher in HPV associated cervical cancer cases $(30.0 \%)$ than in normal controls $(15.0 \%)$, giving an overall
2.86 fold risk for this genotype (OR, 2.86; $95 \% \mathrm{CI}, 1.27$ to 6.44). This risk was increased further when samples were subclassified with respect to tumour stage. Tumours at stage III+IV showed a higher risk (OR, 4.15; 95\% CI, 1.42 to 12.2 ) than those at stage I+II, which showed a moderate risk (OR, 2.24; $95 \% \mathrm{CI}, 0.91$ to 5.5). However, the difference in genotypic distribution between HPV positive and HPV negative cases was not significant $\left(\chi^{2}=0.69\right.$; degrees of freedom $(\mathrm{df})=1 ; \mathrm{p}=0.405)$. This is probably because very few of the cervical tumours were HPV negative.

Table 3 shows the estimated haplotype frequencies among the three p53 polymorphisms in the samples from patients and controls. The p53 haplotypes are expressed in the order: intron 3-codon 72-intron 6. ${ }^{32}$ Among the eight possible haplotypes, five were found in normal samples and six in the patients. The 1-2-2 haplotype was most common in samples from both the patients and the controls, whereas the 1-2-1 haplotype was completely missing in the normal controls. There was a significant difference in overall haplotype frequency distribution between the two groups $\left(\chi^{2}=\right.$ 11.52; df $=5 ; \mathrm{p}=0.042$ ), but no particular haplotype was found to be associated with the patients. However, when haplotypes $1-2-1$ and 1-2-2 were combined, they were found to be associated with cervical carcinogenesis $(\mathrm{OR}=1.77 ; 95 \% \mathrm{CI}, 1.08$ to 2.89$)$.

\section{DISCUSSION}

Since it was first reported in $1998,{ }^{11}$ the hypothesis that p53 codon 72 polymorphism is a predictor of increased HPV associated cervical cancer risk has generated a considerable amount of controversy. ${ }^{11}$ Extensive studies have been carried out throughout the world to reveal the role of the homozygous Arg/Arg genotype as a risk factor for HPV associated cervical carcinogenesis. In populations from southeast Asia-such as Taiwan, Thailand, Korea, Japan, Hong Kong, and China-the homozygous Arg/Arg genotype was not found to be a risk for the development of cervical cancer. ${ }^{33-38}$ Among the Hispanic population from Brazil, Chili, Peru, and in the African population, the Arg/Arg genotype was found to be a risk factor for HPV associated cervical carcinogenesis, ${ }^{39-42}$ although one study from Argentina failed to find an association. ${ }^{43}$ Reports from white populations, particularly in Italy and Sweden, are contradictory. ${ }^{44-46}$

Table 3 Extended haplotype frequencies for patients and normal controls (16 bp-Bst UI-Nci I)

\begin{tabular}{|c|c|c|c|c|c|c|c|}
\hline \multirow[b]{2}{*}{ Population (n) } & \multicolumn{6}{|c|}{ p53 haplotypes } & \multirow[b]{2}{*}{ p Value } \\
\hline & $1-2-2(\%)$ & $1-1-2(\%)$ & $2-1-1(\%)$ & $1-1-1(\%)$ & $2-1-2(\%)$ & $1-2-1(\%)$ & \\
\hline Normal (168) & $70(41.7)$ & $51(30.4)$ & $22(13.1)$ & $14(8.3)$ & $11(6.5)$ & $0(0)$ & \multirow{2}{*}{0.042} \\
\hline Patient (104) & $54(51.9)$ & $25(24.0)$ & $7(6.7)$ & $7(6.7)$ & $7(6.7)$ & $4(3.8)$ & \\
\hline \multicolumn{8}{|c|}{$\begin{array}{l}\text { N, number of chromosomes analysed. } \\
\text { Haplotypes are in the order of: intron 3-codon } 72 \text {-intron } 6 \text {. } \\
1 \text { at an individual locus indicates the absence of a } 16 \text { bp duplication at intron 3, a proline at Bst UI, and the absence of Nci I at intron } 6 \text {. } \\
2 \text { at individual locus indicates the presence of a } 16 \text { bp duplication at intron } 3 \text {, an arginine at Bst Ul, and the presence of Nci I at intron } 6 \text {. }\end{array}$} \\
\hline
\end{tabular}


Studies from France, the Czech Republic, Germany, and the UK were unable to find an association, ${ }^{47-50}$ whereas investigations in Greece, Holland, and Hungary supported the role of the Arg/Arg genotype as a risk factor for HPV associated cervical carcinogenesis. ${ }^{51-53}$ To date, there are five reports from India examining the association between p53 codon 72 polymorphism and the risk of cervical cancer. Three of these reports found a positive association between the p53 arginine homozygous genotype at codon 72 and HPV associated cervical cancer, ${ }^{3054} 55$ whereas one study from southern India failed to find an association..$^{56}$ In addition, there is one report from eastern India stating that proline homozygosity at codon 72 of $\mathrm{p} 53$ is the at risk genotype. ${ }^{57}$ Because the reports from India were contradictory, we investigated the p53 codon 72 polymorphism and two other p53 polymorphisms in patients with cervical cancer from eastern India. There are two recent meta-analyses of the association between the p53 codon 72 polymorphism and cervical cancer. One of these analyses found a slightly increased risk for adenocarcinoma, but not for squamous cell cancer, ${ }^{13}$ suggesting that improvement of the predictive usefulness of the p53 codon 72 polymorphism requires more studies that are designed to address the genetic architecture of the p53 codon 72 polymorphism and other risk factors for cervical cancer. Another study found no association between this polymorphism and preinvasive cervical lesions, or invasive cervical cancer of undefined histology, but found a slightly increased risk for squamous cell cancer and adenocarcinoma. ${ }^{12}$ The authors suggested that two reasons for the contradictory results between these studies are methodological issues in the study designs and confounding by ethnicity. In our present study, both the controls and the patients were taken from the same caste ethnic group, living in the same geographical location.

\section{"The biochemical differences between the two p53 genotypes at codon 72 were elegantly demonstrated by a study showing that the arginine form of the protein was much more susceptible to HPV E6 mediated degradation than the proline form"}

Previously, we reported that various subpopulations within the caste group from eastern India do not differ with respect to allele frequency at several other polymorphic loci. ${ }^{58}$ Thus, the possibility of false associations as a result of population stratification has been ruled out. In addition, in our present study we have included only patients with squamous cell carcinoma of the uterine cervix and have analysed multiple polymorphisms simultaneously. The frequencies of the p53 codon 72 genotypes vary among populations from different countries. In a previous study comprising different ethnic groups, the frequency of arginine homozygotes varied from $12.4 \%$ to $53.4 \%$ across the world..$^{32}$ Within India, the frequency of arginine homozygous individuals varied from $14 \%$ to $25 \%$ in different geographical regions of the country. ${ }^{28555659}$

We found a significant over representation of arginine homozygotes at codon 72 of the p53 gene in the patients with cervical cancer. Genotype differences between the case and control individuals at the two other loci were not significant. In our study, 52 of 61 of the patients were HPV-16/18 positive, with HPV-16 sequences being detected in 37 and HPV-18 in 15 of the HPV positive patients. This is in agreement with earlier studies from India. ${ }^{60-62}$ Arginine homozygotes showed a 2.59 fold higher risk of cervical carcinogenesis, which increased to 2.86 fold when the analysis was restricted to patients with HPV-16/18 positive cervical cancer and normal controls. It was interesting to note that HPV infection increased with the developmental stages of cancer and the presence of the homozygous arginine genotype (tumours at stage I+II: OR, 2.24; 95\% CI, 0.91 to 5.5 and stage III+IV: OR, $4.15 ; 95 \% \mathrm{CI}, 1.42$ to 12.2 ). This supports the hypothesis that individuals with the homozygous arginine genotype are more susceptible to cervical carcinogenesis.

The biochemical differences between the two p53 genotypes at codon 72 were elegantly demonstrated by a study showing that the arginine form of the protein was much more susceptible to HPV E6 mediated degradation than the proline form. ${ }^{11}$ The regulatory role of intronic sequences is being increasingly recognised. ${ }^{63}$ Several workers have reported functional differences between the different p53 intron 3 and 6 polymorphisms. ${ }^{14} 156465$ One study reported lower apoptotic indices and a reduced repair capacity in lymphoblastoid cell lines that harbour the less frequent alleles with the intron 316 bp duplication and intron 6 Nci I polymorphisms. ${ }^{14}$ There were no splicing errors linked to these polymorphisms. ${ }^{15}$ However, in cell culture analyses these two p53 intronic polymorphisms were not sufficient to impair p53 function during the selection process in neoplastic transformation, and an additional coding region mutation was needed. ${ }^{15}$ The intronic change of $\mathrm{G} \rightarrow \mathrm{C}$ at nt 13964 in intron 6 either caused or was linked to a variation leading to stabilisation and possible inactivation of the p53 protein, thereby contributing to tumorigenesis. ${ }^{65}$ Intron 4 of p53 has been predicted to contain several transcription factor binding sites, ${ }^{66}$ and single base pair substitutions in this intron have been shown to disturb the binding of unidentified proteins, resulting in decreased expression of $\mathrm{p} 53 .{ }^{67}$ Inclusion of intron 3 in murine p53 cDNA has been shown to increase the expression of the gene. ${ }^{5}$ Overall, the functional role of the two p53 intronic polymorphisms analysed and their modulatory role in cancer risk remain uncertain. Further studies are needed to reveal any regulatory role of these intronic sequences. Alternatively, these intronic p53 polymorphisms may confer an increase in cancer risk through linkage disequilibrium with a functional variant of the p53 gene.

It has been proposed that the inheritance of specific germline haplotypes based on three biallelic polymorphisms of p53 ( 16 bp duplication in intron 3, codon 72 Arg/Pro, and intron 6 Nci I RFLP at nt 13494) is a better predictor of cancer risk. ${ }^{14}{ }^{18-22}{ }^{28}$ To date, there is no report on specific haplotypes associated with cervical cancer. In our present study, a significant difference in haplotype distribution between the patients with cervical cancer and the normal controls raises the possibility of an association of specific haplotypes with cancer risk $\left(\chi^{2}=11.52 ; \mathrm{df}=5 ; \mathrm{p}=0.042\right)$. Although we were unable to ascertain a specific haplotype with increased cervical cancer risk in strict statistical terms, it is evident that the rare haplotype $1-2-1$ is completely absent in the control subjects, but not in patients, and another haplotype 1-2-2 showed a modest risk $(\mathrm{OR}=1.512 ; 95 \% \mathrm{CI}, 0.92$ to 2.47$)$. This risk was more significant when both the haplotypes, $1-2-1$ and $1-2-2$, were combined (OR, 1.77; 95\% CI, 1.08 to 2.89). However, more samples need to be analysed to support this observation. It is interesting to note that the two haplotypes are different only at the intron 6 Nci I polymorphic site, and both of them contain the arginine allele. This haplotype showed no association in other cancer types, ${ }^{14}{ }^{18-21}$ which could be because of differences in the ethnicity of the populations and in cancer sites between these studies.

We suggest that individuals with the p53 codon 72 arginine homozygous genotype are at greater risk of developing squamous cell carcinoma of the uterine cervix. Evidence in favour of this observation is further strengthened by the fact that the specific haplotypes $1-2-2$ and $1-2-1$ showing a 


\section{Take home messages}

- p53 codon 72 arginine homozygotes appear to be at greater risk of developing squamous cell carcinoma of the uterine cervix

- The high risk haplotypes 1-2-1 and 1-2-2 also contain the arginine allele, further strengthening this conclusion

- More samples need to be analysed to support this observation

greater risk also contain the arginine allele. The association of these haplotypes could result either from strong linkage disequilibrium among these three sites, which we reported previously, ${ }^{28}$ or from the fact that the other two intronic polymorphisms contribute functionally to risk by altering the functional property of nascent RNA expression and/or stabilisation, as discussed above.

\section{ACKNOWLEDGEMENTS}

We are thankful to the Director, Chittaranjan National Cancer Institute, Kolkata, India for providing access to patients. We are grateful to all members of the Human Genetics and Genomics Division of IICB and the Department of Oncogene Regulation of CNCI for their kind cooperation and encouragement during the study. SM, CM, and RS are grateful to the Council of Scientific and Industrial Research, New Delhi, India for predoctoral fellowships. This work was supported by research grants from the Department of Biotechnology (grant number BT/MB/05/002/94) and the Department of Science and Technology (grant number SP/SO/ D-75/96) of The Government of India.

\section{Authors' affiliations}

S Mitra, C Misra, S Roychoudhury, Indian Institute of Chemical Biology,

4, Raja S. C. Mullick Road, Kolkata 700 032, India

R K Singh, C K Panda, Chittaranjan National Cancer Institute, 37, S. P.

Mukherjee Road, Kolkata 700 026, India

\section{REFERENCES}

1 Jayant K, Rao RS, Nene BM, et al. Improved stage at diagnosis of cervical cancer with increased cancer awareness in a rural Indian population. Int J Cancer 1995;63:161-3.

2 Suris JC, Dexeus S. Survival in cervical cancer. Eur J Gynaecol Oncol 1998;19:11-13

3 zur Hausen H. Viruses in human cancers. Science 1991;254:1167-73.

4 Munoz N, Bosch FX, de Sanjose S, et al. Epidemiologic classification of human papillomavirus types associated with cervical cancer. N Engl J Med 2003;348:518-27.

5 Lozano G, Levine AJ. Tissue-specific expression of p53 in transgenic mice is regulated by intron sequences. Mol Carcinog 1991;4:3-9.

6 Filippova M, Parkhurst L, Duerksen-Hughes PJ. The human papillomavirus 16 E6 protein binds to Fas-associated death domain and protects cells from Fastriggered apoptosis. J Biol Chem 2004;279:25729-44.

7 Scheffner M, Werness BA, Huibregtse JM, et al. The E6 oncoprotein encoded by human papillomavirus types 16 and 18 promotes the degradation of $\mathrm{p} 53$. Cell 1990;63:1129-36.

8 Werness BA, Levine AJ, Howley PM. Association of human papillomavirus types 16 and 18 E6 proteins with p53. Science 1990;248:76-9.

9 Horner SM, Defilippis RA, Manuelidis L, et al. Repression of the human papillomavirus E6 gene initiates p53-dependent, telomerase-independent senescence and apoptosis in HeLa cervical carcinoma cells. J Virol 2004;78:4063-73.

10 Soussi T, Beroud C. Assessing TP53 status in human fumours to evaluate clinical outcome. Nat Rev Cancer 2001;1:233-40.

11 Storey A, Thomas M, Kalita A, et al. Role of a p53 polymorphism in the development of human papillomavirus-associated cancer. Nature 1998;393:229-34.

12 Koushik A, Platt RW, Franco EL. p53 codon 72 polymorphism and cervical neoplasia: a meta-analysis review. Cancer Epidemiol Biomarkers Prev 2004;13:11-22.

13 Jee SH, Won SY, Yun JE, et al. Polymorphism of p53 codon-72 and invasive cervical cancer: a meta-analysis. Int J Gynaecol Obstet 2004;85:301-8.

14 Wu X, Zhao H, Amos Cl, et al. p53 genotypes and haplotypes associated with lung cancer susceptibility and ethnicity. J Natl Cancer Inst 2002;94:681-90.
15 Wang-Gohrke S, Weikel W, Risch H, et al. Intron variants of the p53 gene are associated with increased risk for ovarian cancer but not in carriers of BRCA1 or BRCA2 germline mutations. Br J Cancer 1999;81:179-83.

16 Wang-Gohrke S, Becher H, Kreienberg R, et al. Intron 316 bp duplication polymorphism of $\mathrm{p} 53$ is associated with an increased risk for breast cancer by the age of 50 years. Pharmacogenetics 2002;12:269-72.

17 Sialander A, Birgander R, Kivela A, et al. p53 polymorphisms and haplotypes in different ethnic groups. Hum Hered 1995;45:144-9.

18 Sjalander A, Birgander R, Hallmans G, et al. p53 polymorphisms and haplotypes in breast cancer. Carcinogenesis 1996;17:1313-16.

19 Wang-Gohrke S, Rebbeck TR, Besenfelder W, et al. p53 germline polymorphisms are associated with an increased risk for breast cancer in German women. Anticancer Res 1998;18:2095-9.

20 Weston A, Wolff MS, Morabia A. True extended haplotypes of p53: indicators of breast cancer risk. Cancer Genet Cytogenet 1998;102:153-4.

21 Khaliq S, Hameed A, Khaliq T, et al. p53 mutations, polymorphisms, and haplotypes in Pakistani ethnic groups and breast cancer patients. Genet Test 2000:4:23-9.

22 Sjalander A, Birgander R, Athlin L, et al. p53 germ line haplotypes associated with increased risk for colorectal cancer. Carcinogenesis 1995;16:1461-4

23 Miller SA, Dykes DD, Polesky HF. A simple salting out procedure for extracting DNA from human nucleated cells. Nucleic Acids Res 1988;16:1215.

24 D'Costa J, Saranath D, Dedhia P, et al. Detection of HPV-16 genome in human oral cancers and potentially malignant lesions from India. Oral Oncol 1998;34:413-20.

25 Park JS, Dong SM, Kim HS, et al. Detection of pl6 gene alteration in cervical cancer using tissue microdissection and $\mathrm{LOH}$ study. Cancer Lett 1999; 136:101-8

26 Balaram P, Nalinakumari KR, Abraham E, et al. Human papillomaviruses in 91 oral cancers from Indian betel quid chewers - high prevalence and multiplicity of infections. Int J Cancer 1995;61:450-4.

27 Gillison ML, Koch WM, Capone RB, et al. Evidence for a causal association between human papillomavirus and a subset of head and neck cancers. J Natl Cancer Inst 2000;92:709-20.

28 Mitra S, Chatteriee S, Panda CK, et al. Haplotype structure of TP53 locus in Indian population and possible association with head and neck cancer. Ann Hum Genet 2003;67:26-34.

29 Weston A, Pan CF, Ksieski HB, et al. p53 haplotype determination in breast cancer. Cancer Epidemiol Biomarkers Prev 1997:6:105-12.

30 Nagpal JK, Sahni S, Das BR. p53 codon 72 polymorphism and susceptibility to development of human papilloma virus-associated cervical cancer in Indian women. Eur J Clin Invest 2002;32:943-8.

31 Schiffman M. Cervix. In: Schottenfeld D, Fraumeni F, eds. Cancer epidemiology and prevention, 3rd ed. San Francisco: Oxford University Press. [In press.]

32 Sialander A, Birgander R, Saha N, et al. p53 polymorphisms and haplotypes show distinct differences between major ethnic groups. Hum Hered 1996;46:41-8

33 Wu MT, Liu CL, Ho CK, et al. Genetic polymorphism of p53 and XRCC1 in cervical intraepithelial neoplasm in Taiwanese women. $J$ Formos Med Assoc 2004; 103:337-43.

34 Settheetham-Ishida W, Singto $Y$, Yuenyao $P$, et al. Contribution of epigenetic risk factors but not $\mathrm{p} 53$ codon 72 polymorphism to the development of cervical cancer in northeastern Thailand. Cancer Lett 2004;210:205-11.

35 Lee SA, Kim JW, Roh JW, et al. Genetic polymorphisms of GSTM1, p21, p53 and HPV infection with cervical cancer in Korean women. Gynecol Oncol 2004;93:14-18.

36 Nishikawa A, Fujimoto T, Akutagawa N, et al. p53 polymorphism (codon-72) has no correlation with the development and the clinical features of cervical cancer. Int J Gynecol Cancer 2000;10:402-7.

37 Wong YF, Chung TK, Cheung TH, et al. p53 polymorphism and human papillomavirus infection in Hong Kong women with cervical cancer. Gynecol Obstet Invest 2000;50:60-3.

38 Wang NM, Tsai CH, Yeh KT, et al. p53 codon 72Arg polymorphism is not a risk factor for carcinogenesis in the Chinese. Int J Mol Med 1999:4:249-52.

39 Pegoraro RJ, Rom L, Lanning PA, et al. p53 codon 72 polymorphism and human papillomavirus type in relation to cervical cancer in South African women. Int J Gynecol Cancer 2002;12:383-8.

40 de Araujo Souza PS, Villa LL. Genetic susceptibility to infection with human papillomavirus and development of cervical cancer in women in Brazil. Mutat Res 2003;544:375-83.

41 Ojeda JM, Ampuero S, Rojas P, et al. p53 codon 72 polymorphism and risk of cervical cancer. Biol Res 2003;36:279-83.

42 Klug SJ, Wilmotte R, Santos C, et al. TP53 polymorphism, HPV infection, and risk of cervical cancer. Cancer Epidemiol Biomarkers Prev 2001;10:1009-12.

43 Abba MC, Villaverde LM, Gomez MA, et al. The p53 codon 72 genotypes in $\mathrm{HPV}$ infection and cervical disease. Eur J Obstet Gynecol Reprod Biol 2003; 109:63-6.

44 Comar M, Molin GD, Guaschino S, et al. p53 at codon 72 polymorphism, human papillomavirus infection and cervical lesions: a cross-sectional study from northeastern Italy. Eur J Obstet Gynecol Reprod Biol 2004; 1 14:210-14.

45 Gustafsson AC, Guo Z, Hu X, et al. HPV-related cancer susceptibility and p53 codon 72 polymorphism. Acta Dermatol Venereol 2001;81:125-9.

46 Zehbe I, Voglino G, Wilander E, et al. p53 codon 72 polymorphism and various human papillomavirus $16 \mathrm{E} 6$ genotypes are risk factors for cervical cancer development. Cancer Res 2001;61:608-11.

47 Humbey O, Aubin F, Cairey-Remonnay S, et al. TP53 polymorphism at exon 4 in Caucasian women from eastern France: lack of correlation with HPV status and grade of cervical precancerous lesions. Eur J Obstet Gynecol Reprod Biol 2002; 103:60-4. 
48 Tachezy R, Mikyskova I, Salakova M, et al. Correlation between human papillomavirus-associated cervical cancer and p53 codon 72 arginine/ proline polymorphism. Hum Genet 1999;105:564-6.

49 Giannoudis A, Graham DA, Southern SA, et al. p53 codon 72 ARG/PRO polymorphism is not related to HPV type or lesion grade in low- and highgrade squamous intra-epithelial lesions and invasive squamous carcinoma of grade squamous intra-epithelial lesions

50 Klaes R, Ridder R, Schaefer U, et al. No evidence of p53 allele-specific predisposition in human papillomavirus-associated cervical cancer. $J \mathrm{Mo}$ Med 1999;77:299-302.

51 Szarka K, Veress G, Juhasz A, et al. Integration status of virus DNA and p53 codon 72 polymorphism in human papillomavirus type 16 positive cervical cancers. Anticancer Res 2000;20:2161-7.

52 van Duin M. Snijders PJ, Vossen MT, et al. Analysis of human papillomavirus type 16 E6 variants in relation to $\mathrm{p} 53$ codon 72 polymorphism genotypes in cervical carcinogenesis. J Gen Virol 2000;81:317-25.

53 Agorastos T, Lambropoulos AF, Constantinidis TC, et al. p53 codon 72 polymorphism and risk of intra-epithelial and invasive cervical neoplasia in Greek women. Eur J Cancer Prev 2000;9:113-18.

54 Saranath D, Khan Z, Tandle AT, et al. HPV16/18 prevalence in cervical lesions/cancers and p53 genotypes in cervical cancer patients from India. Gynecol Oncol 2002:86:157-62.

55 Katiyar S, Thelma BK, Murthy NS, et al. Polymorphism of the p53 codon 72 Arg/Pro and the risk of HPV type 16/18-associated cervical and oral cancer in India. Mol Cell Biochem 2003;252:117-24.

56 Pillai MR, Sreevidya S, Pollock BH, et al. Polymorphism at codon 72 of p53, human papillomavirus, and cervical cancer in South India. J Cancer Res Clin Oncol 2002;128:627-31.
57 Bhattacharya P, Duttagupta C, Sengupta S. Proline homozygosity in codon 72 of p53: a risk genotype for human papillomavirus related cervical cancer in Indian women. Cancer Lett 2002; 188:207-11

58 Chakravorty M, Ghosh A, Choudhury A, et al. Ethnic differences in allelic structure of IL8 and ILIb gene in populations from Eastern India. Hum Biol 2004;76: 153-9.

59 Tandle AT, Sanghvi V, Saranath D. Determination of p53 genotypes in oral cancer patients from India. Br J Cancer 2001;84:739-42.

60 Mitra AB. Genetic deletion and human papillomavirus infection in cervical cancer: loss of heterozygosity sites at $3 p$ and $5 p$ are important genetic events. Int J Cancer 1999;82:322-4.

61 Munirajan AK, Kannan K, Bhuvarahamurthy V, et al. The status of human papillomavirus and tumor suppressor genes p53 and p16 in carcinomas of uterine cervix from India. Gynecol Oncol 1998:69:205-9.

62 Dasgupta S, Chakraborty SB, Roy A, et al. Differential deletions of chromosome $3 p$ are associated with the development of uterine cervical carcinoma in Indian patients. Mol Pathol 2003;56:263-9.

63 Mattick JS. Introns: evolution and function. Curr Opin Genet Dev 1994:4:823-31.

64 Lehman TA, Haffty BG, Carbone CJ, et al. Elevated frequency and functional activity of a specific germ-line p53 intron mutation in familial breast cancer. Cancer Res 2000;60:1062-9.

65 Avigad S, Barel D, Blau O, et al. A novel germ line p53 mutation in intron 6 in diverse childhood malignancies. Oncogene 1997;14:1541-5.

66 Shamsher M, Montano X. Analysis of intron 4 of the p53 gene in human cutaneous melanoma. Gene 1996;176:259-62.

67 Beenken SW, Karsenty G, Raycroft L, et al. An intron binding protein is required for transformation ability of p53. Nucleic Acids Res $1991 ; 19: 4747-52$ 